\title{
Poor Adherence to Common Recommendations and Associated Factors among Outpatients with Type 2 Diabetes Mellitus in a Police Hospital of Ethiopia
}

\author{
${ }^{1}$ Research Directorate, St. Paul's Hospital Millennium Medical \\ College, Addis Ababa, Ethiopia \\ 2Pharmacy Department, Ethiopian Federal Police Referral Hospital, \\ Addis Ababa, Ethiopia \\ ${ }^{3}$ Institute of Health Policy, Management, and Evaluation, University \\ of Toronto, Canada; Toronto Health Economics and Technology \\ Assessment (THETA) Collaborative, University Health Network, \\ Canada.
}

Tariku Shimels ${ }^{1}$ Melesse Abebaw ${ }^{2}$ Gebremedhin Beedemariam Gebretekle ${ }^{3}$

\author{
Address for correspondence Tariku Shimels (BPharm, BA, MSc), \\ St. Paul's Hospital Millennium Medical College, Addis Ababa, \\ Ethiopia (e-mail: tarphar2008@gmail.com),P.O.Box: 1271..
}

J Soc Health Diab 2021;9:e8-e14.

\begin{abstract}
Keywords

- Ethiopia

- cross-sectional study

- police hospital

- poor adherence

- type 2 diabetes mellitus

Introduction Poor adherence to medication and healthy lifestyle managements, such as diet and regular exercise, remains to be a challenge for patients with type 2 diabetes mellitus. The objective of this study was to assess the pattern of adherence to common recommendations, reasons, and factors associated with poor overall adherence among outpatients with type 2 diabetes mellitus in a police hospital of Ethiopia. Method A facility-based cross-sectional study was done between 15 October 2016 and 15 January 2017. Systematic random sampling method was applied to recruit participants. A semistructured interview guide with an observation checklist was used to collect data. SPSS v.20.0 was used in the analysis.

Results Out of 361 participants, over half (56.5\%) participants were male and 235 $(65.1 \%)$ participants were military. Nearly half $(49 \%)$ of the participants were on oral combination therapy. Only 194 (53.7\%) of the patients showed good adherence for diet. Half $(50.1 \%)$ of the respondents had poor adherence to all recommendations. Reasons for poor adherence included lack of adequate knowledge (68.9\%) for diet, carelessness (37.8\%) for exercise, and lack of adequate knowledge (34.8\%) followed by carelessness (28.3\%) and forgetfulness (19.6\%) for medication. Intake of herbal medicines doubled the likelihood of good adherence.

Conclusion Adherence of patients to diet was found to be suboptimal. Lack of adequate knowledge, carelessness, and forgetfulness were among the reasons mentioned. Only use of herbal medicine showed statistical significance with adherence. Patient education on dietary practice is required in the study setting.
\end{abstract}

\section{Introduction}

Diabetes mellitus (DM) is a complex metabolic disorder which requires proper adherence medication, diet and lifestyle to improve quality of life and reduce morbidity and mortality. ${ }^{1}$ Though the disease had been considered as a concern of developed nations, ${ }^{2-5}$ its appearance in developing countries like Ethiopia, accounts a devastating double burden. ${ }^{6,7}$
DOI https://doi.org/

$10.1055 / \mathrm{s}-0041-1732783$

ISSN 2321-0656 (c) 2021. Novo Nordisk Education Foundation.

This is an open access article published by Thieme under the terms of the Creative Commons Attribution-NonDerivative-NonCommercial-License, permitting copying and reproduction so long as the original work is given appropriate credit. Contents may not be used for commercial purposes, or adapted, remixed, transformed or built upon. (https://creativecommons.org/licenses/by-nc-nd/4.0/).

Thieme Medical and Scientific Publishers Pvt. Ltd. A-12, 2nd Floor, Sector 2, Noida-201301 UP, India 
A report has shown that DM was one of the top two causes of admission to hospitals in Ethiopia. ${ }^{8}$ A report documented in 2014 by the International Diabetes Federation (IDF) revealed that nearly 4.9 million Ethiopians aged between 20 and 79 live with DM. ${ }^{9}$

All DM management guidelines and associations recommend for screening, diagnostic, and therapeutic actions that are known or believed to favorably affect health outcomes of patients with the disease. ${ }^{1-3,9,10}$ Besides, achievement of glycemic, blood pressure, and lipid targets, particularly in patients with type 2 diabetes mellitus (T2DM), has a direct relationship with appropriate adherence to diet, regular exercise as well as antidiabetic medications. .,2,9-12 $^{1}$

Poor adherence to medication and healthy lifestyle managements such as diet and regular exercise remains to be a challenge for patients with T2DM. Consequently, a significant number of patients are not adequately benefited from diabetes treatments, which in turn end up with further complications, lower quality of life, and increased health-care costs. ${ }^{13,14}$ On the other hand, proper medication adherence is reported to significantly save T2DM health-care costs and reduce hospitalization rates. ${ }^{15}$

In Ethiopia, certain facility-based cross-sectional studies have been conducted to assess the pattern of poor adherence to antidiabetic medications. ${ }^{16-20}$ Consequently, findings ranging from 15 to $45 \%$ have been documented in different regions of the country. These studies raised several factors to contribute for poor adherence including depression symptoms and side effects, ${ }^{16}$ level of education and duration of diabetes, ${ }^{17}$ level of income, ${ }^{18}$ uses of alternative medicine, ${ }^{19}$ and knowledge and availability of medications ${ }^{20}$ among others. These results, however, are all based on patients with DM attending public hospitals sharing of similar culture and setting. In addition, adherence was considered with emphasis to medication recommendations only. A population with quite different lifestyle and culture, to the general population, was considered for this study to assess the pattern of adherence against common recommendations in diabetes management.

Another variation in this combined adherence study, from most of the previous studies, is that how it assumed of good and poor adherence. Some observational studies and clinical trials have reported an average of 43 to $78 \%$ adherence rates for most chronic illnesses., ${ }^{21,22}$ Nonetheless, there is no clear-cut indication on the literature for what level of adherence is adequate. Certain trials considered $80 \%$ rate as a mark for adequate while others mentioned more than $95 \%$, specially, in cases of serious infections like HIV. ${ }^{23}$

This study has considered a rate of $80 \%$ for measuring medication adherence with a dichotomous classification as good and poor. This was so because, the evaluation has incorporated dietary and exercise adherence elements that could not be addressed by adherence measuring models. ${ }^{24}$ In addition, the data collection was mainly relied on a medication refill database to minimize self-reported recall biases that often is a limitation of adherence measurement models..$^{25,26}$

The objective of the present study, therefore, was to assess the pattern of adherence to diet, exercise, and medication recommendations set in different national and international guidelines. ${ }^{1,2,9-12}$ Meanwhile, common reasons of poor adherence to the respective recommendations and factors associated with poor overall adherence were also studied among outpatients with T2DM attending the chronic care clinic of Federal Police Referral Hospital, Addis Ababa, Ethiopia.

\section{Methods}

\section{Study Design and Setting}

A health facility-based cross-sectional study was done at Federal Police Referral Hospital (FPRH), Addis Ababa, Ethiopia between 15 October 2016 and 15 January 2017. The facility is the only referral police hospital in the country and delivers a bundle of medical services to an estimated 1,800 inpatients and 22,000 outpatients annually. Although most services are provided to federal and regional police members and their respective families, limited numbers of government bodies also receive coverage through a contractual basis.

\section{Source and Study Population}

Source population of this study was all outpatients who visited the chronic care clinic of FPRH during the study period, while the study population was the all outpatients with T2DM and fulfilled the inclusion criteria.

\section{Inclusion and Exclusion Criteria}

Inclusion criteria considered for the study were patients who were a member of either the federal or regional police commission, those who had at least 1-year follow-up at the chronic care clinic, those with complete medical history in their chart or database records, aged $\geq 18$ years and willing to participate in the interview. Meanwhile, patients who were either unable to recall or doubted their lifestyle or medication adherence condition in the past 3 months or interrupted their medication refill to the chronic care pharmacy database for the same refill period were excluded from the study.

\section{Sample Size and Sampling Technique}

The sample size was estimated using the single population proportion formula ${ }^{27}$ considering 50\% magnitude of poor-adherence to lifestyle recommendations among patients with T2DM. A total of 414 patients with T2DM was required by considering $p=50 \%$, precision $=2 \%$, and $\alpha=0.05$. A final sample size correction formula ${ }^{27}$ and $10 \%$ nonresponse rate were assumed as well.

Systematic random sampling method was used to select participants. Initially, the total number of participants was identified based on their follow-up dates at the chronic care clinic and chronic care pharmacy unit database. As refills were done every 3 months, the sampling interval was determined by dividing the total number of patients with T2DM to the required sample size. Accordingly, a random serial number between zero and the sampling interval was drawn, and selection continued till the end based on the subject's appointment date to refill the medications. 


\section{Data Collection Procedure and Quality}

Data was acquired using a semistructured interview guide and an observation checklist. A trained pharmacist was employed and interview was scheduled based on participants' medication refill date. After obtaining their consent, participants were briefed about the purpose of the study and invited to participate. Sociodemographic characteristics, disease history, and adherence issues, to common recommendations, were recorded by interviewing participants. Medication charts were reviewed for patients with doubtful medication records in the chronic care pharmacy database.

To ensure consistency, clarity, and data quality, interview was conducted in Amharic (Ethiopian working language). Data collectors were trained for 2 days on the relevance of the study, data collection techniques, informed consent, and confidentiality of data to be collected. Prior to the actual data collection, a pilot of 30 patients' medication records, obtained from the chronic care clinic, was evaluated against the required variables in the study. Pretest data was not included in the main study. Completeness of data collected was checked every day by the principal investigators.

\section{Operational Definitions}

Poor adherence: Adherence measured against the recommendations mentioned below, and when one fails to fulfill all the requirements to be classified as good adherence as set in the different guidelines. . $^{1,29-12}$

Dietary adherence: It was measured based on vegetable, fiber, salt, fat and alcohol intake levels. It was considered good if all of the following were satisfied in the query: participant reports to take at least two servings of vegetables/fruits for $\geq 3$ days/week; whole grains, fiber, or fish at least two servings for $\geq 3$ days/week, less than $2.3 \mathrm{~g}$ salt ( $<1 \mathrm{TSF}$ ) intake per day, and $\geq 600 \mathrm{~mL}$ ( 2 bottles) of alcoholic intake per day. Lower fat and sugar intakes were assumed based on patients' subjective view of "small."

Exercise adherence: It was considered active if participant reported to exercise for at least 30 minutes in $\geq 4$ days of the week.

Medication adherence: It was measured based on a participant's reported daily missed doses of the prescribed antidiabetic medications. If participant has not missed more than $80 \%$ of the doses in a month, it was assumed good adherence.

Overall adherence: It was measured based on the dietary, exercise, and medication adherences mentioned above. If participant adheres to all, overall adherence was considered good. If participant reports to miss any, it was assumed poor.

\section{Ethics Approval and Consent}

The study was approved by the School of Pharmacy Research and Ethics Committee, College of Health Sciences, Addis Ababa University. Permission was obtained from Federal Police Health Service Directorate. The study was conducted with an informed verbal consent acquired from each participant. Patients were assured to withdraw from the interview at any moment if they feel uncomfortable. Any personal identifier was not included during the data collection or analysis.

\section{Data Analysis}

After coding and checked manually for completeness, data was entered into statistical product and service solutions (SPSS) v.20.0 and cleaned before analysis. Descriptive

Table 1 Characteristics of patients with T2DM attending the chronic care clinic of Federal Police Referral Hospital, Addis Ababa, Ethiopia, $2017(n=361)$

\begin{tabular}{|l|l|l|l|}
\hline Characteristics & Category & Frequency & Percent \\
\hline \multirow{2}{*}{ Age } & $\leq 45$ years & 150 & 41.6 \\
\cline { 2 - 4 } & $46-60$ years & 127 & 35.2 \\
\cline { 2 - 4 } & $>60$ years & 84 & 23.3 \\
\hline \multirow{2}{*}{ Gender } & Female & 157 & 43.5 \\
\hline Military status & Male & 204 & 56.5 \\
\hline Marital status & Military & 235 & 65.1 \\
\hline \multirow{2}{*}{ Comorbidity } & Nonmilitary & 126 & 34.9 \\
\hline \multirow{2}{*}{ Type of therapy } & Married & 355 & 98.3 \\
\hline \multirow{2}{*}{ Duration of therapy (y) } & Unmarried & 6 & 1.7 \\
\hline & No & 152 & 42.1 \\
\hline & Yes & 209 & 57.9 \\
\hline & Oral monotherapy & 54 & 15.0 \\
\hline & Oral combination therapy & 177 & 49.0 \\
\hline & Insulin mono/combination therapy & 51 & 14.1 \\
\hline
\end{tabular}

Abbreviation: T2DM, type 2 diabetes mellitus. 
statistics was used to present results. A multivariable binary logistics regression was performed to determining factors associated with overall adherence to common recommendations in T2DM.

\section{Results}

\section{Characteristics of Study Participants}

A total of 414 participants were required for the study of which 361 participants were successfully interviewed, and considered for further analysis (response rate $=87 \%$ ). The mean age was 54.8 years with standard deviation \pm 11.9 years. Duration of treatment ranged from 1 to 31 years with mean age of 6.7 years.

More than half $(56.5 \%)$ of the patients were males and almost all (98.3\%) were married. About two-third (58\%) of the respondents had at least one type of comorbidity with hypertension accounting the highest proportion 145 (40.2\%) of the comorbidities followed by dyslipidemia (30.5\%). About half ( $49 \%$ ) of participants were taking oral combination therapy and most $(60.1 \%)$ of them had $\leq 5$ years of treatment duration (-Table 1 ).

\section{Pattern of Adherence to Common Recommendations}

Half $(50.1 \%)$ of the study participants had poor adherence to common recommendations (diet, exercise, and medication). Specifically, most (53.7\%) of the participants had good adherence to diet, although it is lower as compared with their adherence to exercise (87.5\%) and medications (87.3\%) (-Table 2).

\section{Common Reasons of Poor Adherence}

Reasons of poor adherence to particular recommendations were also examined and majority (68.9\%) of participants reported lack of knowledge as a major reason to poor dietary adherence, whereas lack of knowledge was the least likely reason for poor adherence to exercise (2.2\%). Most (37.8\%) of the participants had reported that carelessness was their main cause to poor adherence to exercise. Poor adherence to antidiabetic medication was mainly attributed to lack of knowledge as reported by 16 (34.8\%) patients followed by carelessness (28.3\%) (-Table 3 ).

Table 2 Level of adherence to common recommendations among patients with T2DM attending the chronic care clinic of Federal Police Referral Hospital, Addis Ababa, Ethiopia, $2017(n=361)$

\begin{tabular}{|l|l|l|}
\hline Recommendation & Good (\%) & Poor (\%) \\
\hline Adherence to diet & $194(53.7)$ & $167(46.3)$ \\
\hline Adherence to exercise & $316(87.5)$ & $45(12.5)$ \\
\hline Adherence to medication & $315(87.3)$ & $46(12.7)$ \\
\hline Overall adherence & $180(49.9)$ & $181(50.1)$ \\
\hline
\end{tabular}

Abbreviation: T2DM, type 2 diabetes mellitus.

\section{Factors Associated with Overall Adherence to Common Recommendations}

The bivariate analysis did not show a significant association between good adherence and the independent factors (age, gender, military status, and comorbid condition, use of herbal medicine, duration, and type of therapy). However, multivariable analysis revealed that those who were not using herbal medicine had lower chance to good adherence (adjusted odds ratio $[\mathrm{AOR}]=0.56 ; 95 \%$ confidence interval $[\mathrm{CI}]=0.34,0.94)$ compared with those who took herbal drugs.

\section{Discussion}

Paying a careful attention to adherence of medication and lifestyle changes is an integral part of controlling T2DM targets. The present study has assessed the status of adherence on common recommendations among patients of T2DM in a military hospital setting.

Adherence of the patients to medication and exercise was found to be superior ( $87.5 \%$ and $87.3 \%$, respectively) as compared with adherence to diet (53.7\%). A similar finding has been reported among nonmilitary population in north eastern part of the country. ${ }^{17}$ This higher adherence to exercise could be attributed to the population considered where military trainings and habits might have influenced their knowledge and perception on benefits of exercise. A study conducted in Botswana also documented that poor adherence to exercise was linked to lack of information and perception that exercise may exacerbate illness. ${ }^{28}$ Similarly, medication is available free of charge for police members that may have a contribution to the observed high adherence, though free of charge

Table 3 Reasons for poor adherence to common recommendations among patients with T2DM attending the chronic care clinic of Federal Police Referral Hospital, 2017

\begin{tabular}{|l|l|l|}
\hline Variable & Reasons reported & Frequency (\%) \\
\hline $\begin{array}{l}\text { Poor adherence to diet } \\
(n=167)\end{array}$ & Lack of knowledge & $115(68.9)$ \\
& Lack of income & $25(15.0)$ \\
& Carelessness & $19(11.4)$ \\
& Lack of taste & $8(4.8)$ \\
& Lack of access & $6(3.6)$ \\
& Discomfort/ & $5(3.3)$ \\
& dyspepsia & \\
\hline $\begin{array}{l}\text { Poor adherence to } \\
\text { exercise }(n=45)\end{array}$ & Carelessness & $17(37.8)$ \\
& Unable to walk/ & $14(31.1)$ \\
& move & $13(28.9)$ \\
\hline Poor adherence to & Lack of knowledge & $1(2.2)$ \\
medication $(n=46)$ & Depression & \\
& Lack of knowledge & $16(34.8)$ \\
& Carelessness & $13(28.3)$ \\
& Forgetfulness & $9(19.6)$ \\
& Fear of adverse drug & $4(8.7)$ \\
reaction & $2(4.3)$ \\
& Lack of diet & $2(4.3)$ \\
& Side effect of drugs & \\
\hline
\end{tabular}

Abbreviation: T2DM, type 2 diabetes mellitus. 
does not, necessarily, predict good adherence. ${ }^{29}$ The result is also in agreement with findings from the sub-Saharan and the Western countries which reported that out of pocket payments and unavailability of antidiabetic medications hindered patients' adherence to medications. ${ }^{20,30,31}$ Nevertheless, the overall adherence to common recommendations in this study was poor and this calls for mechanisms to devise mechanisms to improve patient awareness.

Of the patients with poor adherence to diet, more than two-third (68.9\%) reported "lack of adequate knowledge" as their prior reason followed by those who mentioned “"carelessness" as a cause for their poor adherence behavior (11.4\%). These reasons were also mentioned by a cross-sectional study conducted in Botswana, ${ }^{28}$ while not getting nutritional education in hospitals was reported to have a significant association with patients' poor dietary adherence in Addis Ababa. ${ }^{32}$ This shows that individualized dietary education is not gaining place as part of diabetes management in health facilities despite stringent recommendations in multiple guidelines. ${ }^{1-3,9,10,12}$ In another literature that reviewed 53 articles, it was reported that educational interventions via simple illustrated content, especially, among low literacy patients improved adherence to medication and lifestyle changes. $^{33}$

On the other hand, poor adherence to exercise and medication, in this study, was found to be accounted by "carelessness," "forgetfulness," "lack of adequate knowledge," and being "unable to move or walk." A cross-sectional study conducted among elderly chronic patients of an Indian hospital has documented that patients' lack of knowledge about the disease, inadequate knowledge about therapy, and difficulty to refill medications on time were among the top reasons for poor adherence. ${ }^{34}$ In another longitudinal self-reported adherence measurement by Aikens and Piette, ${ }^{35}$ forgetfulness and carelessness were found to be the most reported reasons for nonadherence, which, in turn, were significantly associated with concurrent and subsequent glycemic control.

Only use of herbal medicine in the multivariate analysis, showed a statistically significant association. The subjects who were not using herbal medicine had a half chance for good adherence compared with those who used herbal medicine. This is in contrast to findings obtained in Northwest Ethiopia ${ }^{17}$ and Eastern Uganda ${ }^{36}$ which reported that avoidance of herbal medicine use improved medication adherence. The uncommon relationship observed in our study, however, needs a further scrutiny. While low consumption could be due to several factors such as patients' knowledge, perception, or access to herbal drugs, this, in turn, might be implicated to their behavior of good adherence to recommendations.

This assessment has tried to evaluate a combination of commonly known adherence recommendations in the management of T2DM. The results have also shown baseline adherence issues and patterns, typically, relevant in military settings. However, the study is not without limitations pertinent to the way it assumed to classify adherence and the exhaustiveness of the data collection method it employed. Although database records do not show actual medication utilization, biases could also be inevitable from patients' self-reports.

\section{Conclusion}

Majority of the study participants had good adherence to exercise and medication but poor adherence to diet. Half of the participants had had poor overall adherence to diet, exercise, and medication recommendations. Lack of knowledge, carelessness, and forgetfulness were the key reasons for poor adherence. Only use of herbal medicine was significantly associated with overall adherence; patient education and counseling on individualized T2DM management strategies should be practiced in the study setting.

Table 4 Factors associated with adherence among patients with T2DM attending the chronic care clinic of Federal Police Referral Hospital, Addis Ababa, Ethiopia, 2017 ( $n=361)$

\begin{tabular}{|c|c|c|c|c|c|}
\hline \multirow[t]{2}{*}{ Variable } & & \multicolumn{2}{|c|}{ Overall adherence } & \multirow{2}{*}{$\begin{array}{l}\text { COR } \\
(95 \% \mathrm{CI})\end{array}$} & \multirow{2}{*}{$\begin{array}{l}\text { AOR } \\
(95 \% \mathrm{Cl})\end{array}$} \\
\hline & & Good (\%) & Poor (\%) & & \\
\hline Age (y) & $\begin{array}{l}\leq 45 \\
46-60 \\
>60\end{array}$ & $\begin{array}{l}85(56.7) \\
56(44.1) \\
40(47.6)\end{array}$ & $\begin{array}{l}65(43.3) \\
71(55.9) \\
44(52.2)\end{array}$ & $\begin{array}{l}1.44(0.84,2.46) \\
0.87(0.50,1.51) \\
1.00\end{array}$ & $\begin{array}{l}1.70(0.92,3.16) \\
0.84(0.43,1.51) \\
1.00\end{array}$ \\
\hline Gender & $\begin{array}{l}\text { Male } \\
\text { Female }\end{array}$ & $\begin{array}{l}105(51.5) \\
76(48.4)\end{array}$ & $\begin{array}{l}99(48.5) \\
81(51.6)\end{array}$ & $\begin{array}{l}0.86(0.58,1.34) \\
1.00\end{array}$ & $\begin{array}{l}0.94(0.60,1.45) \\
1.00\end{array}$ \\
\hline Military status & $\begin{array}{l}\text { Military } \\
\text { Nonmilitary }\end{array}$ & $\begin{array}{l}115(48.9) \\
66(52.4)\end{array}$ & $\begin{array}{l}120(51.1) \\
60(47.6)\end{array}$ & $\begin{array}{l}0.87(0.57,1.34) \\
1.00\end{array}$ & $\begin{array}{l}0.13(0.02,1.20) \\
1.00\end{array}$ \\
\hline Comorbidity & $\begin{array}{l}\text { No } \\
\text { Yes }\end{array}$ & $\begin{array}{l}71(46.7) \\
111(52.6)\end{array}$ & $\begin{array}{l}81(53.3) \\
99(47.4)\end{array}$ & $\begin{array}{l}0.79(0.52,1.20) \\
1.00\end{array}$ & $\begin{array}{l}0.76(0.48,1.20) \\
1.00\end{array}$ \\
\hline $\begin{array}{l}\text { Use of herbal } \\
\text { medicine }\end{array}$ & $\begin{array}{l}\text { No } \\
\text { Yes }\end{array}$ & $\begin{array}{l}131(47.5) \\
50(58.8)\end{array}$ & $\begin{array}{l}145(52.5) \\
35(41.2)\end{array}$ & $\begin{array}{l}0.63(0.39,1.04) \\
1.00\end{array}$ & $\begin{array}{l}0.56(0.34,0.94) \\
1.00\end{array}$ \\
\hline $\begin{array}{l}\text { Duration of therapy } \\
\text { (y) }\end{array}$ & $\begin{array}{l}\leq 5 \\
>5\end{array}$ & $\begin{array}{l}110(50.7) \\
71(49.3)\end{array}$ & $\begin{array}{l}107(49.3) \\
73(50.7)\end{array}$ & $\begin{array}{l}1.00 \\
0.95(0.62,1.44)\end{array}$ & $\begin{array}{l}1.00 \\
1.06(0.64,1.77)\end{array}$ \\
\hline Type of therapy & $\begin{array}{l}\text { Oral monotherapy } \\
\text { Oral combination } \\
\text { Insulin monotherapy/combination } \\
\text { Insulin +oral combination }\end{array}$ & $\begin{array}{l}25(46.3) \\
91(51.4) \\
23(45.1) \\
42(53.2)\end{array}$ & $\begin{array}{l}29(53.7) \\
86(48.6) \\
28(54.9) \\
37(46.8)\end{array}$ & $\begin{array}{l}0.76(0.38,1.52) \\
0.93(0.55,1.59) \\
0.72(0.36,1.47) \\
1.00\end{array}$ & $\begin{array}{l}0.85(0.40,1.80) \\
0.92(0.51,1.65) \\
0.69(0.33,1.430 \\
1.00\end{array}$ \\
\hline
\end{tabular}

Abbreviations: AOR, adjusted odds ratio; $\mathrm{Cl}$, confidence interval; $\mathrm{COR}$, crude odds ratio. 


\section{Competing Interests}

The authors declare that they have no competing interests.

\section{Acknowledgments}

We would like to thank the staff members of the chronic care clinic and chronic care pharmacy unit of Federal Police Referral Hospital for their unreserved support during the conduct of this study. We, also, forward our deepest gratitude to the outpatients with T2DM and who have given informed consent to participate in this study.

\section{References}

1 American Diabetes Association. Standards of Medical Care in Diabetes-2014. Diabetes Care 2014;17(S1) :s14-s79

2 International Diabetes Federation [webpage on the Internet]. IDF Diabetes Atlas, Sixth Edition; 2014. Available from: www. idf.org/sites/default/files/EN_6E_Atlas_Full_0.pdf. Accessed June 27, 2021

3 Centers for Disease Control and Prevention. National Diabetes Statistics Report: Estimates of Diabetes and its Burden in the United States; 2014. Available from: https://www.cdc.gov/ diabetes/.../statsreport14/national-diabetes-report-web.pdf. Accessed June 27, 2021

4 Cheng YJ, Imperatore G, Geiss LS, et al. Secular changes in the age-specific prevalence of diabetes among U.S. adults: 1988-2010. Diabetes Care 2013;36(9):2690-2696

5 Selvin E, Parrinello CM, Sacks DB, Coresh J. Trends in prevalence and control of diabetes in the United States, 1988-1994 and 1999-2010. Ann Intern Med 2014;160(8):517-525

6 Lasky D, Becerra E, Boto W, Otim M, Ntambi J. Obesity and gender differences in the risk of type 2 diabetes mellitus in Uganda. Nutrition 2002;18(5):417-421

7 Tesfaye T, Shikur B, Shimels T, Firdu N. Prevalence and factors associated with diabetes mellitus and impaired fasting glucose level among members of federal police commission residing in Addis Ababa, Ethiopia. BMC Endocr Disord 2016;16(1):68

8 Lester FT, Tsega E. The pattern of adult medical admissions in Addis Ababa, Ethiopia. East Afr Med J 1976;53(11):620-634

9 International Diabetes Federation. IDF Diabetes Atlas. 6th edition. Brussels, Belgium: International Diabetes Federation, 2014. http://www.idf.org/diabetesatlas/update-2014. Accessed June 27, 2021

10 Ethiopian Diabetes Association. Adama, Ethiopia. 2009. http:// www.diabetesethiopia.org.et/. Accessed June 27, 2021

11 Kang AY, Park SK, Park SY, et al. Therapeutic target achievement in type 2 diabetic patients after hyperglycemia, hypertension, dyslipidemia management. Diabetes Metab J 2011;35(3):264-272

12 American Diabetes Association. Standards of medical care in diabetes-2016. Diabetes Care 2016;39(suppl 1):S1-S106

13 Nasseh K, Frazee SG, Visaria J, Vlahiotis A, Tian Y. Cost of medication nonadherence associated with diabetes, hypertension, and dyslipidemia. Am J Pharm Benefits 2012;4(2):e41-e47

14 Roebuck MC, Liberman JN, Gemmill-Toyama M, Brennan TA. Medication adherence leads to lower health care use and costs despite increased drug spending. Health Aff (Millwood 2011;30(1):91-99

15 Jha AK, Aubert RE, Yao J, Teagarden JR, Epstein RS. Greater adherence to diabetes drugs is linked to less hospital use and could save nearly $\$ 5$ billion annually. Health Aff (Millwood 2012;31(8):1836-1846

16 Teklay G, Hussein T, Tesfaye D. Non adherence and associated factors among type 2 diabetes patients at Jimma
University Specialized Hospital, Southwest Ethiopia. J med Sci 2013;13(7):578-584

17 Abebaw M, Messle A, Hailu M, Zewdu F. Adherence and associated factors towards anti diabetic medication among type 2 diabetic patients on follow up at University of Gondar Hospital, Northwest Ethiopia. Adv Nurs 2016;•••10.1155/2016/8579157

18 Kassahun A, Gashe F, Mulisa E, Rike WA. Nonadherence and factors affecting adherence of diabetic patients to anti-diabetic medication in Assela General Hospital, Oromia Region, Ethiopia. J Pharm Bioallied Sci 2016;8(2):124-129

19 Abebe SM, Berhane Y, Worku A. Barriers to diabetes medication adherence in North West Ethiopia. Springerplus 2014;3:19510.1186/2193-1801-3-195

20 Ali M, Alemu T, Sada O. Medication adherence and its associated factors among diabetic patients at Zewditu Memorial Hospital, Addis Ababa, Ethiopia. BMC Res Notes 2017;10:676.

21 Cramer J, Rosenheck R, Kirk G, Krol W, Krystal J; VA Naltrexone Study Group 425. Medication compliance feedback and monitoring in a clinical trial: predictors and outcomes. Value Health 2003;6(5):566-573

22 Claxton AJ, Cramer J, Pierce C. A systematic review of the associations between dose regimens and medication compliance. Clin Ther 2001;23(8):1296-1310

23 Osterberg L, Blaschke T. Adherence to medication. N Engl J Med 2005;353(5):487-497

24 Morisky DE, Green LW, Levine DM. Concurrent and predictive validity of a self-reported measure of medication adherence. Med Care 1986;24(1):67-74

25 Ruddy K, Mayer E, Partridge A. Patient adherence and persistence with oral anticancer treatment. CA Cancer J Clin 2009;59(1):56-66

26 Jasti S, Siega-Riz AM, Cogswell ME, Hartzema AG. Correction for errors in measuring adherence to prenatal multivitamin/mineral supplement use among low-income women. J Nutr 2006;136(2):479-483

27 Berenson, ML, Levine DM, and Szabat K. Estimation and Sample Size Determination for Finite Populations. Basic Business Statistics: Global Edition. 2013. Available on: https:// www.alnap.org/help-library/estimation-and-sample-size-determination-for-finite-populations-basic-business. Accessed June 27, 2021

28 Ganiyu AB, Mabuza LH, Malete NH, Govender I, Ogunbanjo GA. Non-adherence to diet and exercise recommendations amongst patients with type 2 diabetes mellitus attending Extension II Clinic in Botswana. Afr J Prim Health Care Fam Med 2013;5(1):45710.4102/ phcfm.v5i1.457

29 Rwegerera GM, Moshomo T, Gaenamong M, et al. Antidiabetic medication adherence and associated factors among patients in Botswana; implications for the future. Alex J Med 2018;54:103-109

30 Rwegerera GM. Adherence to anti-diabetic drugs among patients with Type 2 diabetes mellitus at Muhimbili National Hospital, Dar es Salaam, Tanzania- A cross-sectional study. Pan Afr Med J 2014;17:25210.11604/pamj.2014.17.252.2972

31 Polonsky WH, Henry RR, Henry RR. Poor medication adherence in type 2 diabetes: recognizing the scope of the problem and its key contributors. Patient Prefer Adherence 2016;10:1299-1307

32 Worku A, Mekonnen Abebe S, Wassie MM. Dietary practice and associated factors among type 2 diabetic patients: a cross sectional hospital based study, Addis Ababa, Ethiopia. Springerplus 2015;4:1510.1186/s40064-015-0785-1

33 Zullig LL, Gellad WF, Moaddeb J, et al. Improving diabetes medication adherence: successful, scalable interventions. Patient Prefer Adherence 2015;9:139-149

34 Roy NT, Sajith M, Bansode MP. Assessment of factors associated with low adherence to pharmacotherapy in elderly patients. J Young Pharm 2017;9(2):272-276 
Poor Adherence to Common Recommendations and Associated Factors among Outpatients with T2DM in a Police e14 Hospital of Ethiopia Shimels et al.

35 Aikens JE, Piette JD. Longitudinal association between medication adherence and glycaemic control in type 2 diabetes. Diabet Med 2013;30(3):338-344
36 Bagonza J, Rutebemberwa E, Bazeyo W. Adherence to anti diabetic medication among patients with diabetes in eastern Uganda; a cross sectional study. BMC Health Serv Res 2015;15:16810.1186/s12913-015-0820-5 